\title{
Determination of the Hole-flangeability for thin Sheets
}

\author{
Feliks Stachowicz ${ }^{1}$ \\ ${ }^{1}$ Rzeszow University of Technology, Powstańców Warszawy 8, 35-959 Rzeszów, Poland
}

\begin{abstract}
Sheet metal stretching is one of the most frequently applied sheets forming operation in the industry. Hole flanging is a common sheet forming operation to produce structural sheet metal components. Flanges are used for appearance, rigidity, hidden joints, and strengthening of the edge of sheet metal parts. Trial-end-error is the most common approach for tooling and process design in flanging operations. This paper presents some experimental results of hole-flanging process performed on flat deep drawing steel sheets with circular hole drilled or punched in the centre of blank. Three punches of different geometry i.e. cylindrical, hemispherical and conical were used in this experiment. The effect of both the punch geometry and material mechanical parameters (especially strain hardening and plastic anisotropy) on the limit expansion of the hole, limit strain dependence on hole performing technology as well as sheet thickness distribution along collar formed was determined.
\end{abstract}

Keywords: hole flanging, forming limit, strain hardening, plastic anisotropy, thickness distribution.

\section{Introduction}

Collars performed by hole flanging are used to provide material for thread cutting and to provide additional support for press fits for bolts or for making solder connections with tubes [1,2]. The modern automobile industry and the household appliance industry have demanded precision products for single part or multiple manufacture parts so that the related industrial product precision size of press forming has gradually been required. Hole flanging is a process in which a sheet blank, with a hole in its center, is rigidly clamped around its periphery by a blank holder, and then a punch is used to force the blank into a die to form a hollow flanged component. Although the process is simple, many technical problems in manufacturing, the accuracy of the component shape, the limitations of stretchability, fractures arising from the stretched surface, and the estimation of the punch load, are revealed.

In the hole flanging, a multi loading with tangential tensile and radial compressive stress arises. During the process, the sheet is bent twice, once around the punch radius and again around die radius. Therefore, the conventional approaches based on tensile instability are not always sufficient to determine the limit formability. The greatest strains are in the periphery of the expanded hole - the major deformation increases the diameter of the initial hole while thickness is reduced. However, the tensile stress in the circumferential direction at the edge of flanged hole is the main cause of failure due to cracking or tearing [3]. General method to predict the material fracture in the process of forming analysis make use of the fracture strain of the specimen obtained by simple tension test, the limit strain based on plastic 
instability theory, and the ductile fracture criteria. But the hole-expanding process is different from general forming process because the side face of the hole has no constrains and the fracture propagates trough the side face of a plate during the process [4].

The hole flanging process is limited to a certain limit hole diameter below which material failure could take place. The stretch flangeability is decreased by not only small ductility of sheet material but also small quality of the sheared edges. The magnitude of the deformation of flanged parts is usually characterized by the drawing ratio $\beta$, which is defined as a ratio of the inside diameter $d$ of the finished collar to the initial hole diameter $d_{0}$ (Fig. 1). The limit value of drawing ratio $\beta_{\max ^{\prime}}$ very often is known as Hole Expanding Limit (HEL) [5] and depends on several different parameters $[5 \div 10]$ :

\section{$\checkmark$ mechanical properties of sheet material,}

$\checkmark$ the surface quality of the initial hole edge,

$\checkmark$ geometry of forming punch,

$\checkmark$ relative hole diameter,

$\checkmark$ friction conditions.

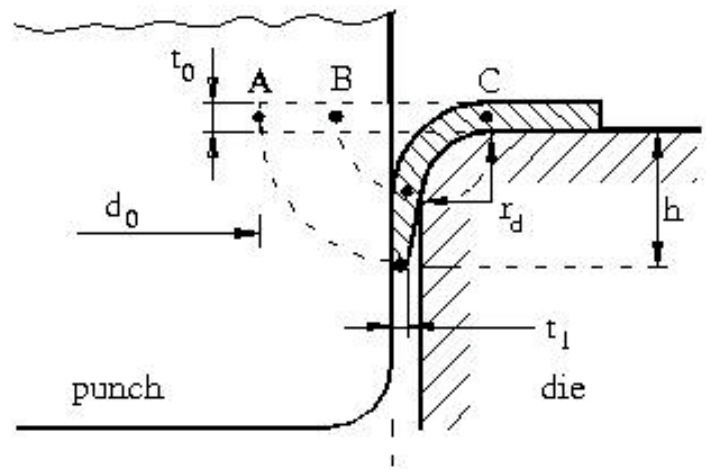

Fig. 1: Schematic diagram of hole flanging.

To be able to predict the flange hole formed to a specific geometry with a given material, including diameter of the expanded hole and the flange height, it can save a lot of effort in contrast to the conventional trial-end-error approach. This work aims to investigate the influence of punch geometry: cylindrical (flat-bottomed), hemispherical and conical, as well as mechanical parameters of deep drawing steel sheet metal on the value of hole expanding limit, the value limit strain on hole edge and sheet thickness distribution along collar.

\section{Material and Experimental Procedure}

The tests were carried out on three different kinds of $1.0 \mathrm{~mm}$ thick steel sheet: DQ drawing quality, DDQ deep drawing quality and EDQ extra drawing quality. Tensile specimens of $240 \mathrm{~mm}$ gauge length and $20 \mathrm{~mm}$ width were prepared from strips cut at $0^{\circ}, 45^{\circ}$ and $90^{\circ}$ to the rolling direction of the strip. The experiments were carried out using a special device, which recorded simultaneously the tensile load, the current length and the current width of the specimens. The effective stress - effective strain relationship was described using the Hollomon model in the form of $\sigma=\mathrm{C} \varepsilon^{\text {n }}$.

The plastic anisotropy factor $\boldsymbol{r}$ has been determined on the basis of the relationship between the width strain and thickness strain in the whole range of specimen elongation using less square method. The value of the tensile parameters (Table I) has been averaged according to: $\mathrm{x}_{\text {mean }}=$ $\left(\mathrm{x}_{0}+2 \mathrm{x}_{45}+\mathrm{x}_{90}\right) / 4$, where the subscripts refer to specimen orientation.

The flanging test was carried out using a special device constructed according to the proposal of standard method [5]. Three punch shapes - conical, cylindrical and spherical were prepared for the axisymmetric collar-drawing test. The punch and die geometry was as follow:

$\checkmark$ punch diameter $-D_{p}=30 \mathrm{~mm}$,

$\checkmark$ die diameter $-D_{d}=32 \mathrm{~mm}$, die edge radius $-r d=2 \mathrm{~mm}$,

$\checkmark$ conical end angle $-a=600$,

$\checkmark$ radius of cylindrical punch edge $-r_{p}=4 \mathrm{~mm}$.

Sheet specimens $80 \times 80 \mathrm{~mm}$, prepared from the strips with marked orientation according to the rolling direction and with drilled or punched $d_{0}=10 \mathrm{~mm}$ central hole, were firmly clamped at the periphery and deformed progressively up to visible strain localization at the hole edge. Expansion of the hole was recorded using the digital photo-camera and stored as a *.pws files. Using professional computer code, the *.pws files were elaborated in order to determine changes in a hole diameter in rolling direction and transverse rolling direction.

After flanging process the collar height was measured. The sample performed by hole flanging of the EDQ steel sheet, with drilled initial hole, where cut along its main diameter and polished due to determine sheet thickness distribution. Starting from hole edge sheet thickness was measured at 20 points in $0.75 \mathrm{~mm}$ distance. 
Tab. 1: Mechanical properties of DQ, DDQ and EDQ steel sheet

\begin{tabular}{|c|c|c|c|c|c|c|}
\hline \multirow{2}{*}{$\begin{array}{l}\text { Material symbol and } \\
\text { specimen orientation }\end{array}$} & \multirow{2}{*}{$\begin{array}{l}\text { Yield stress } \\
R 0,2 \text { [MPa] }\end{array}$} & \multirow{2}{*}{$\begin{array}{l}\text { Ultimate strength } \\
R m[\mathrm{MPa}]\end{array}$} & \multirow{2}{*}{$\begin{array}{l}\text { Ultimate elongation } \\
\varepsilon u\end{array}$} & \multicolumn{2}{|c|}{ Strain hardening parameters } & \multirow{2}{*}{$\begin{array}{l}\text { Anisotropy factor } \\
r\end{array}$} \\
\hline & & & & $\mathrm{C}[\mathrm{MPa}]$ & $n$ & \\
\hline DQ_0 & 193 & 351 & 0.36 & 554 & 0.166 & 1.218 \\
\hline DQ_45 & 197 & 372 & 0.32 & 591 & 0.171 & 0.946 \\
\hline DQ_90 & 193 & 353 & 0.34 & 563 & 0.174 & 1.410 \\
\hline Mean value & 196 & 362 & 0.34 & 575 & 0.171 & 1.130 \\
\hline DDQ_0 & 196 & 336 & 0.42 & 557 & 0.192 & 1.464 \\
\hline DDQ_45 & 196 & 336 & 0.38 & 547 & 0.183 & 1.180 \\
\hline DDQ_90 & 198 & 311 & 0.41 & 526 & 0.177 & 1.902 \\
\hline Mean value & 196 & 330 & 0.40 & 544 & 0.184 & 1.432 \\
\hline EDQ_0 & 151 & 282 & 0.44 & 494 & 0.221 & 1.630 \\
\hline EDQ_45 & 153 & 293 & 0.40 & 497 & 0.207 & 1.445 \\
\hline EDQ_90 & 153 & 281 & 0.42 & 475 & 0.210 & 2.031 \\
\hline Mean value & 153 & 287 & 0.42 & 487 & 0.211 & 1.638 \\
\hline
\end{tabular}

\section{Results and Discussion}

Maximum diameter of expanded hole (Table II) visibly depends on both the punch geometry and sheet material type. When the punch geometry is concerned the largest hole expansion was achieved when flanging with the conical punch and the worst in the case of the cylindrical (flat-bottomed) punch. For the conical and spherical punches, the edges of the hole are in contact with the punch surface so that severe friction in the tangential direction is produced, reduces the thinning of the wall and protects the hole periphery from necking or tearing. Additionally the strain state in flanging with conical punch seemed to be the most beneficial, which resulted also in the lowest collar height in comparison with other punch shapes $[11,12]$.

Since formability of a sheet metal strongly depends on the plastic properties of the material, e.g. the value of both the strain hardening exponent $\mathrm{n}$ and plastic anisotropy factor $\mathrm{r}$, as well as initial hole performing technology, the effect of these three parameters on sheet flangeability was examined in our investigations. For all three punch geometry the final hole diameter (before strain localization) increases with the $n$-value increase. This relation is more distinct in the case of initial hole punched (Fig. 2). According to the experimental results we can conclude that the limit value of drawing ratio $\beta_{\max }=3.0$ were achieved in the case of initial hole (Fig. 2):

$\checkmark$ performed by drilling technology for EDQ steel sheet for all three punch geometry, and for DDQ steel sheet when using conical punch, $\checkmark$ performed by punching technology for EDQ steel sheet when using conical punch.

At the hole edge (point A in Fig. 1) material points undergo uniaxial tensile stress and the value of maximum true strain at these points could be calculated as: $\varepsilon=\ln \left(\mathrm{d} / \mathrm{d}_{0}\right)$. Comparisons between maximum true strains calculated on the basis of the tensile test and hole expanding test demonstrated large differences. The values of maximum strain at the hole edge are nearly to 3 times larger (depending on material and technology of initial hole performing) than the value of maximum strain obtained in uniaxial tensile tests. Larger maximum strains at the hole edge observed in the hole expanding test resulted from interaction between outer and inner material points of flange [1], which delay the moment of strain localization and material failure. Formability of sheet metal could be expressed by the $\boldsymbol{n} \cdot \boldsymbol{r}$ factor, defined as product of strain hardening exponent and plastic anisotropy ratio. The value of strain at the hole edge dependence on the value of $\boldsymbol{n} \cdot \boldsymbol{r}$ factor for all three punches shape is more visible in the case of initial hole performed punching technology (Fig. 3). 
Tab. 2: Maximum diameter (in $\mathrm{mm}$ ) of hole expanded using different punch shape and technology of initial hole performing

\begin{tabular}{|l|l|l|l|}
\hline \multirow{2}{*}{ Material symbol } & \multicolumn{3}{|c|}{ Punch geometry } \\
\cline { 2 - 4 } & Cylindrical shape & \multicolumn{1}{|c|}{ Conical shape } & Spherical shape \\
\hline \multicolumn{4}{|c|}{ Initial hole drilled } \\
\hline DQ & 23.03 & 26.32 & 24.12 \\
\hline DDQ & 26.80 & 30.00 & 28.23 \\
\hline EDQ & 30.00 & 30.00 & 30.00 \\
\hline \multicolumn{4}{|c|}{ Initial hole punched } \\
\hline DQ & 16.34 & 20.01 & 18.06 \\
\hline DDQ & 20.17 & 24.22 & 22.26 \\
\hline EDQ & 24.67 & 30.00 & 26.76 \\
\hline
\end{tabular}

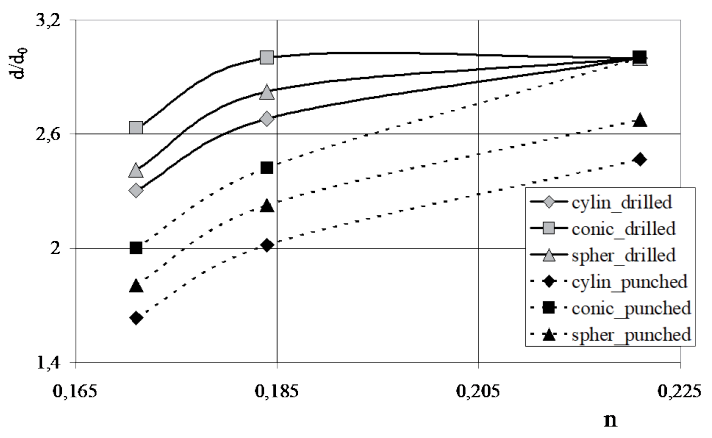

Fig. 2: Hole Expanding Limit $\left(d / d_{0}\right)$ dependence on the value of strain hardening exponent and initial hole performing technology

The results of sheet thickness distribution determination (Fig. 4) demonstrate the largest sheet thinning after flanging process using cylindrical (flat bottomed) punch. At the hole edge visible strain localization was observed in the form of small groove. It is also noteworthy to mention that in this case the collar height was the largest. As it was expected the most uniform sheet thickness distribution was observed after flanging process using the punch with conical shape. In this case the collar height was the smallest.

\section{Conclusions}

On the basis of the experimental results the following conclusions could be formulated:

$\checkmark$ although a sheet material at the hole periphery undergoes uniaxial tensile stresses the maximum strains at the hole edge are nearly 3 times larger than the value of maximum strain obtained in uniaxial tensile test,

$\checkmark$ HEL visibly depends on the punch shape; when using the conical punch, the largest final hole diameter, i.e. hole expanding limit, could

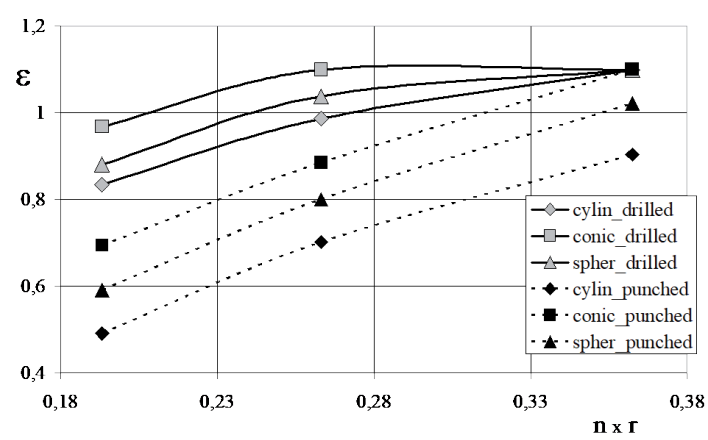

Fig. 3: Strain at hole edge dependence on the value of $n \cdot r$ factor for different initial hole performing technology

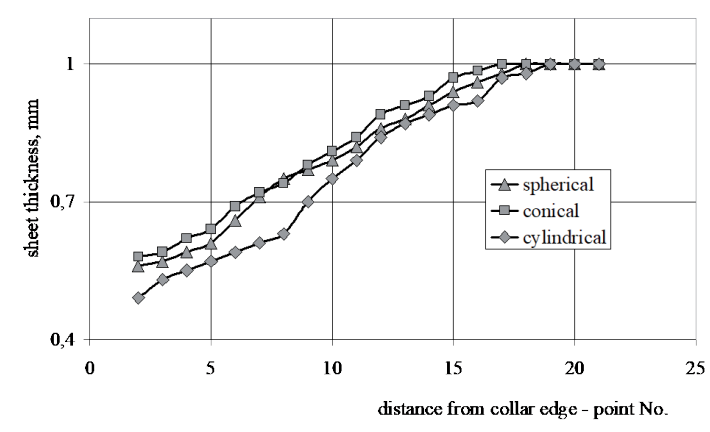

Fig. 4: Sheet thickness distribution along collar performed using different punch shape for EDQ steel sheet, drilled initial hole

be achieved,

$\checkmark$ HEL increases with the strain hardening exponent and plastic anisotropy (n॰r factor), especially in the case of flanging with cylindrical punch,

$\checkmark$ HEL in the case of drilled initial hole was generally larger than that of punched initial hole,

$\checkmark$ the collar height and sheet thickness distribution visibly depend on punch shape - in the case of conical punch the smallest sheet thinning resulted in the smallest collar height.

\section{References and Notes}

[1] Erbel S., Kuczyński K., Marciniak Z. (1981). Obróbka plastyczna. WNT. Warszawa.

[2] Lange K. (1985). Handbook of Metal Forming. McGraw-Hill Co. New York.

[3] Hokoyama T., Nakano H., Kuwabara T.: Fracture prediction of hole expansion forming using forming limit stress criterion. AIP Conf. Proc. 1896, 020024 (2017).

[4] Nikhare C.P.: Analysis of hole expansion limit trough biaxial test, Materials Today: Proc., 5 (2018) 44-50.

[5] Huang Y-M. (2007). An elasto-plastic finite element analysis of the sweet metal stretch flanging process. International 
Journal of Advances in Manufacturing Technology, 34, 641648.

[6] Ko Y.K, Lee J.S., Huh H., Kim H.K, Park S.H. (2007). Prediction of fracture in hub-hole expanding process using a new ductile fracture criterion. Journal of Materials Processing Technology, 187-188, 358-362.

[7] Hayashi H., Urabe T., Hisamatsu S., Nagai Y. (1996). Investigation for standardizing hole-expanding test for evaluat $\neg$ ing stretch flangeability. IDDRG WB 1996, Eger, pp. WG3 1-6.

[8] Huang $\boldsymbol{Y}$-M., Chien $\boldsymbol{K}$-H. (2001). The formability limitation of the hole-flanging process. Journal of Materials Processing Technology, 117, 45-51.

[9] Hyun D.I., Oak S.M., Kang S.S., and Moon Y.M. (2002). Estimation of hole flangeability for high strength steel plates. Journal of Materials Processing Technology, 130-131, 9-13.

[10] Thipprakmas S., Jin M., Murakawa M. (2007). Study of flanged shapes in fine-blanked-hole flanging process (FB-hole flanging process) using finite element method (FEM). Journal of Materials Processing Technology, 192-193, 128-133.

[11] Uthaisangsuk V., Prahl U., Bleck W. (2009). Stretch-flangeability characterization of multiphase steel using a microstructure based failure modeling. Computational Materials Science, 45, 617-623.

[12] Mori K., Abe Y., Soziu Y. (2010). Improvement of stretch flangeability of ultra high strength steel sheet by smoothing of sheared edge. Journal of Materials Processing Technology, 210, 653-659.

[13] Chen X., Jiang H., Cui Z., Lian C., Lu C.: Hole expansion characteristics of ultra high strength steels, Procedia Eng., 81 (2014) 718-723.

[14] Sitek M., Stachowicz F. (2004). Wpływ geometrii stempla na stopień wywinięcia obrzeża otworu. Rudy i Metale Nieżelazne, 49, 60-64.

[15] Li C-L., Huang Y-M., Isai Y-W. (2008). The analysis of forming limit in re-penetration process of hole-flanging of sheet metal. Journal of Materials Processing Technology, 201, 256-260.

\section{Biographical notes}

Feliks Stachowicz, Prof. dr hab. inż., full professor, Year of birth 1951. Graduate of the Faculty of Non-Ferrous Metals at AGH University of Science and Technology in Kraków (1975), he specializes in evaluating metals usability for cold working processes (especially forming limits of thin sheet metal) and analyses of basic parameters concerning technological forming processes of sheet metal, pipes and structural profiles as well as recycling processes. In 1981 he defended PhD degree at the Faculty of Non-Ferrous Metals, AGH University of Science and Technology, in 1991 obtained DSc degree at the Faculty of Mechanical Engineering and Automation, Warsaw University of Technology, and in 2000 he was awarded the professor's degree. In 1999-2002 and 2005-2008 dean of Faculty of Mechanical Engineering and Aeronautics, in 2008-2012 vice rector for general affairs of Rzeszow University of Technology. He is the author or co-author of over 150 papers and four books. 